\title{
Serving larger portions of fruits and vegetables together at dinner promotes intake of both foods among young children
}

\author{
Kevin C. Mathias, MS [Pre-doctoral student], \\ University of North Carolina, 123 W Franklin St., CB\# 8120 University Square, Chapel Hill, NC \\ 27516, Tel: (919)-966-1735, Fax: (919) 966-9159, At the time of the research: Center for Obesity \\ Research and Education, Temple University, Philadelphia PA
}

\section{Barbara J. Rolls, PhD [Professor and Guthrie Chair],}

Department of Nutritional Sciences, The Pennsylvania State University, 226 HendersonUniversity Park, PA 16802, Tel: (814) 863-8572, Fax: (814) 863-8574

\section{Leann L. Birch, PhD [Distinguished Professor of Human Development],}

The Pennsylvania State University, Center for Childhood Obesity Research, 129 Noll BuildingUniversity Park, PA 16802, Tel: (814) 863-0053, Fax: (814)-863-0057

\section{Tanja V.E. Kral, PhD [Assistant Professor of Nursing],}

Department of Biobehavioral Health Sciences, University of Pennsylvania School of Medicine, 418 Curie Blvd, Room 308 Philadelphia, PA 19104-4217, Tel: (215) 573-7512, Fax: (215)

$573-7507$

\section{Elizabeth L. Hanna [Project Coordinator],}

Temple University, Center for Obesity Research and Education, 3223 North Broad St Suite 175, Philadelphia, PA 19140, Tel: (215) 707-8383, Fax: (215) 707-6475

Adam Davey, PhD [Associate Professor, Director], and

Doctoral Program in Health Ecology, Temple University,1301 Cecil B. Moore Avenue, Ritte $r$ Annex 9th floor (004-09) Philadelphia, PA 19122, Tel: (215) 204-7881, Fax: (215)-204-1854

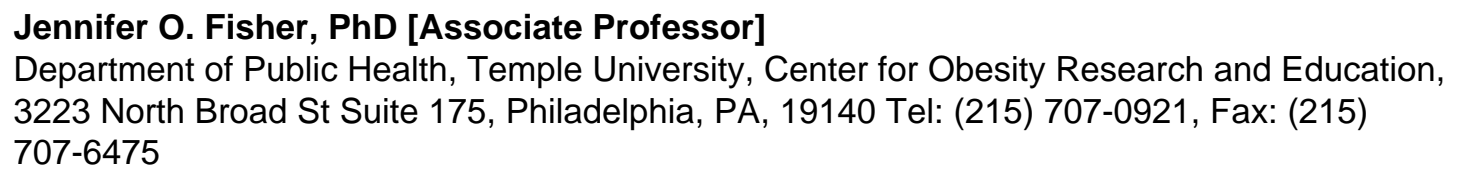

Kevin C. Mathias: kmathias@unc.edu; Barbara J. Rolls: bjr4@psu.edu; Leann L. Birch: llb15@psu.edu; Tanja V.E. Kral: tkral@nursing.upenn.edu; Elizabeth L. Hanna: elizabeth.hanna@temple.edu; Adam Davey: Adam.Davey@temple.edu; Jennifer O. Fisher: jofisher@temple.edu

\begin{abstract}
Serving larger portions of energy dense foods has been shown to promote children's energy intake at meals. Whether larger portions increase children's intake of both fruits and vegetables $(\mathrm{F} \& \mathrm{~V})$ is less clear. A $2 \times 2$ within-subjects design systematically varied portion sizes of fruit $(75 \mathrm{vs} .150 \mathrm{~g})$ and vegetable ( 75 vs. $150 \mathrm{~g}$ ) side dishes served at dinner. Children's F\&V liking was measured
\end{abstract}

(C) 2011 The American Dietetic Association. Published by Elsevier Inc. All rights reserved.

Author to whom correspondence and reprint requests should be addressed: Jennifer Orlet Fisher, PhD, Department of Public Health, Temple University, Center for Obesity Research and Education, 3223 N. Broad Street, Suite 175, Philadelphia, PA 19140, jofisher@temple.edu.

Publisher's Disclaimer: This is a PDF file of an unedited manuscript that has been accepted for publication. As a service to our customers we are providing this early version of the manuscript. The manuscript will undergo copyediting, typesetting, and review of the resulting proof before it is published in its final citable form. Please note that during the production process errors may be discovered which could affect the content, and all legal disclaimers that apply to the journal pertain. 
using a validated tasting method. Thirty 4 - to 6-year-olds were tested in a laboratory setting at 5:00 PM on weekdays from November 2008 through March 2009. Mixed linear models were used to determine effects of fruit portion size, vegetable portion size, and their interaction on food and energy intakes. Data are presented as model-based means \pm standard error unless otherwise indicated. When portions were doubled, children increased their vegetable intake by $37 \%(12 \pm 4$ $\mathrm{g} ; \mathrm{P}<0.01)$ and their fruit intake by $70 \%(41 \pm 6 \mathrm{~g} ; \mathrm{P}<0.01)$. Vegetable portion size effects were not influenced by offering more fruit and vice versa. Portion size effects were limited to children who liked that particular food. Total meal energy intake did not vary by portion size condition. These results indicate that serving larger $F \& V$ portions at meals can be used to promote young children's intake of both foods without influencing total meal energy intake. Effects were not seen in children who disliked $\mathrm{F} \& \mathrm{~V}$, suggesting a need to combine increased $\mathrm{F} \& \mathrm{~V}$ portions with strategies to increase their acceptance.

\section{Keywords}

children; portion size; fruit; vegetables; intake; liking

\section{Introduction}

Despite the initiation of the 5-A-Day for Better Health program in 1991, children's intakes of fruits and vegetables $(\mathrm{F} \& \mathrm{~V})$ remain below recommended levels $(1,2)$. One potential method to promote $\mathrm{F} \& \mathrm{~V}$ intake is to increase the portion sizes served at snacks and meals. Doubling portion sizes of energy-dense entrées has been shown to increase food intake by 25-60\% among 5- to 9-year-old children (3-6). These effects have been observed among children of varying age, sex, race/ethnicity and weight status (7) and are thought to be partially explained by size-related visual cues (7) and inflated consumption norms (8).To date, only a few studies have researched the effect of portion size on young children's intake of low energy density foods such as F\&V (9-11).

Studies that have incorporated more vegetables into the main entrée (9), or offered increased amounts of vegetables with a side of dip prior to the meal (10) have demonstrated benefits for vegetable intake among preschool-aged children. Kral and colleagues (11) found that doubling the portion sizes of applesauce, cooked broccoli, and carrot side dishes served along with a pasta entrée increased fruit intake by $43 \%$ among 5- to 6-year-old children. Increasing the broccoli portion size was only effective in promoting intake among overweight/obese children or those who preferred the broccoli over all other foods served at the meal (11). Because the portion sizes of both F\&V were increased simultaneously, the extent to which the observed effects on vegetable intake were influenced by the amount of fruit served is unclear. Though $F \& V$ are often grouped together, it is well appreciated that young children accept fruits more readily than vegetables (12). Based on this observation it was hypothesized that vegetable portion size effects would be affected by the amount of fruit served. A second hypothesis tested was that given the central role of food preferences in children's consumption patterns $(13,14)$, portion size effects would be determined by the degree of liking a particular food.

\section{Methods}

\section{Sample Size Calculations}

Our previous portion size research led us to expect that effect sizes $\searrow 0.75$ would be clinically meaningful with $\searrow 0.5$ within-subject correlations $(4,7)$. Based on these assumptions, with $\alpha=0.05$, a sample size 230 yields power $\geq 0.8$ for main effects and 
interactions. We expected approximately $80 \%$ completion rates for all study conditions, therefore 38 children were recruited.

\section{Participants}

Participants were 38 children and their primary caregivers living in the greater metropolitan area of Philadelphia, PA. The convenience sample was recruited using advertising in a local pediatric/dental clinic, and an internet classified advertisement site. Eligible children were 4-6 years of age who rated the main entrée as tasting either "yummy" or "just-okay." Three children were excluded at the beginning of the study due to disliking the main entrée. To examine the role of liking in $\mathrm{F} \& \mathrm{~V}$ portion size effects, children had to like either the fruit or vegetable used in the experiment, but not necessarily both. One child disliked both the F\&V and was excluded from the study. Four children ate negligible amounts of both foods $(<10 \mathrm{~g}$ of fruit and $<10 \mathrm{~g}$ of vegetable) at more than half of the visits, and were therefore excluded from the analysis. Children were also excluded from the study if they had severe food allergies, chronic illnesses, conditions affecting food intake, or were on a special diet. Participants were compensated $\$ 30$ for each of their visits and received a $\$ 100$ bonus if they attended all visits. All procedures and measures were approved by the Temple University Institutional Review Board, and parents provided written consent for their own participation and the participation of their child.

\section{Design}

A $2 \times 2$ within-subjects design was used to evaluate the effects of vegetable portion size ( $75 \mathrm{~g}$ vs. $150 \mathrm{~g}$ ), fruit portion size ( $75 \mathrm{~g}$ vs. $150 \mathrm{~g}$ ), and their interaction on children's food and energy intakes at dinner meals. Fruit and vegetable side dishes, along with pasta, milk and dressing were provided in each of the four experimental conditions. Test visits were spaced one week apart to minimize carry-over effects. Children ate dinner with the same group of two to three children in all experimental conditions. Each group of children was randomly assigned one of 12 counterbalanced presentation orders. Previous research was used to identify $\mathrm{F} \& \mathrm{~V}$ of potentially moderate liking by young children (15).

\section{Procedure}

Children and a primary caregiver visited an observational laboratory on Temple University's Health Sciences Campus in Philadelphia, PA once a week for five weeks. The first visit was used to familiarize the children to the research setting, staff members, and the procedures. A child's liking and preference of the foods on the experimental menu, anthropometric measurements, and caregiver self-reports were also assessed during this visit. At the beginning of each visit, parents were asked to report any sleeping problems, illnesses, or medication taken by their child in the previous 24 hours. Parents were asked to refrain from giving any food or beverages to their child two hours prior to arrival and to report any deviations from these instructions. A trained staff member sat at the table during the meal to ensure that procedures were followed, including preventing children from sharing foods, noting dropped foods, and redirecting food related conversation. The children were given 20 minutes to eat dinner. To minimize visual comparisons of portion sizes, all children in the same group were served the same experimental condition. Children were instructed to eat as little or as much as they liked.

\section{Experimental Menu}

The Table depicts the amounts, energy-density $(\mathrm{kcal} / \mathrm{g})$, and types of foods that were served at each experimental condition. Fixed portions of rotini pasta (204 g; SanGiorgio, Harrisburg, PA) with tomato sauce (106 g; Prego, Traditional, Campbell Soup Co., Camden, NJ), 2\% milk (Acme Markets, Supervalu Inc., Eden Prairie, MN) and a side of light ranch 
dressing (Hidden Valley, The Clorox Company, Oakland, CA) were offered in all conditions. Only the portion sizes of the drained canned peaches in light syrup (Del Monte, San Francisco, CA), and cooked broccoli (Birds Eye, Baby Broccoli Florets Rochester, NY) were manipulated. In the interest of matching the energy-density of the F\&V, three grams of butter were added (Shop Rite, Wakefern Food Corporation, Edison, NJ) for every $72 \mathrm{~g}$ of cooked broccoli. The pasta, broccoli, and peaches were all served on a $101 / 4$ inch-diameter three-compartment plate.

The broccoli reference portion size $(75 \mathrm{~g})$ fell between the $50^{\text {th }}$ and $75^{\text {th }}$ percentiles and the reference peach portion size $(75 \mathrm{~g})$ was between the $75^{\text {th }}$ and $90^{\text {th }}$ percentiles of reported intake of those foods for 2- to 5-year old children participating in the Continuing Survey of Food Intakes of Individuals (16). The amounts of milk (244 g) and the main entrée (310 g) were chosen based on previous work with children of a similar age as the subjects in this study (11); the entree amount fell between the $75^{\text {th }}$ and $90^{\text {th }}$ percentiles of spaghetti and tomato sauce intake for children 2-5 years old (16). The amount of dressing $(31 \mathrm{~g})$ served was based on the manufacturer's recommendation for a single serving. The energy-density of the foods was calculated using manufacturer's nutrition labels except the peaches which was determined by a bomb calorimetry assay performed at NP Analytical Laboratories, St. Louis, MO.

\section{Measures}

Children's F\&V Liking and Preference-A validated tasting method $(13,17)$ using cartoon faces was administered to assess children's liking of the F\&V side dishes and relative preferences compared to other foods served at the meal. Children were presented with a small amount of each food and instructed to take a bite/sip and categorize the food as tasting either "yummy," "yucky," or "just okay." Children were then asked to rank-order the same food items based on relative preference.

Weighed Food Intake-Children's food intakes were measured to the nearest $0.1 \mathrm{~g}$ using electronic balances (Model PL6001-S, Mettler Toledo, Columbus, OH).

Demographics-The parent's self-reported demographic information including race/ ethnicity, and employment status.

Weight Status-Heights and weights were obtained in duplicate following procedures described by Lohman (18). Heights were measured to the nearest $0.1 \mathrm{~cm}$ using a wallmounted stadiometer (Harpenden, Holtain Ltd., Crymych, Pembrokeshire, United Kingdom). Weights were measured to the nearest $0.1 \mathrm{~kg}$ using an electronic physician's scale (Model 758C, Cardinal, Webb City, MO). Body mass index (BMI) age- and sexspecific percentiles and z-scores for children were calculated based on the $2000 \mathrm{CDC}$ growth charts using SAS (version 9.2, 2008, SAS Institute Inc, Cary, NC).

\section{Statistical Analysis}

Statistical analyses were conducted using SAS. Primary outcomes were children's F\&V intakes (g). Secondary outcomes were intakes (kcal) of each food as well as total energy intakes. Mixed linear models with repeated measures were used to conduct two-way factorial analyses of variance to test the effects of vegetable portion size ( $75 \mathrm{~g}$ vs. $150 \mathrm{~g})$, fruit portion size ( $75 \mathrm{~g}$ vs. $150 \mathrm{~g}$ ), and their interaction on children's food and energy intakes. In addition to counterbalancing the order the experimental conditions were served to different groups, the effect of changes in intake over time was included in preliminary models and found to not significantly affect portion size effects for fruit $(\mathrm{P}=0.27)$ or vegetable $(\mathrm{P}=0.59)$ intakes; therefore it was not included in any of the final models. Due to 
the non-normality of residuals in some of the models, Wilcoxon Signed-Rank tests were conducted to confirm that the results from the mixed models were robust. Paired t-tests were used to separately test changes in fruit or vegetable intake across reference and large portions for children who rated the foods as "just okay" or "yummy." This post-hoc approach was taken given zero variance in the intake of fruits or vegetables of children who dislike those foods. Significance levels were set at $\mathrm{P}<0.05$ for all statistical tests. Data are presented as model-based means \pm standard error.

\section{Results and Discussion}

\section{Participants}

The 30 children included in the analyses were $5.4 \pm 0.2$ years old, with a mean BMI-foragepercentile of $72.3 \pm 5.4$. Half of the children were classified as overweight or obese ( $285^{\text {th }}$ percentile) (19), and half of the primary care-givers had part-time or full-time employment. Of the 30 children, 18 were female, 14 were Non-Hispanic Black/African American, nine were Non-Hispanic White, and seven were Hispanic White.

\section{Fruit and Vegetable Intakes}

As shown in Figure 1, children consumed $41 \pm 6 \mathrm{~g}$ or $70 \%$ more fruit in the large portion conditions than in the reference conditions ( $59 \pm 5 \mathrm{~g}$ vs. $101 \pm 9 \mathrm{~g}$; $\mathrm{P}<0.0001)$, which corresponds to a $2 / 5^{\text {th }}$ of a serving increase $(20,21)$. As shown in Figure 2 , children consumed $12 \pm 4 \mathrm{~g}$ or $37 \%$ more of the vegetable side dish in the large portion conditions than in the reference conditions ( $32 \pm 6 \mathrm{~g}$ vs. $44 \pm 9 \mathrm{~g} ; \mathrm{P}<0.01$ ). Thirteen of 30 children ate negligible amounts of the vegetable $(<10 \mathrm{~g})$ in more than half of all conditions. For the other 17 children, doubling the vegetable portion size resulted in a $20 \pm 7 \mathrm{~g}$ or $37 \%$ increase in vegetable intake ( $56 \pm 5 \mathrm{~g}$ vs. $77 \pm 9 \mathrm{~g} ; \mathrm{P}<0.01)$, which corresponds to a $1 / 5^{\text {th }}$ of a serving increase $(20,21)$. Increasing the portion size of fruit did not affect vegetable intake and vice versa (Figures $1 \& 2$ ). Effects of fruit or vegetable portion size did not interact with each other $(\mathrm{P}=0.91)$; in other words the intake promoting effect of larger portions on vegetable intake was not affected by serving larger portions of fruit and vice versa.

\section{Effects of Fruit and Vegetable Liking}

Twenty six children rated the fruit as tasting "yummy," three as tasting "just ok" and one as tasting "yucky." Children who rated the fruit as "yummy," "just ok" and "yucky" ate on average $82 \pm 7 \mathrm{~g}, 98 \pm 12 \mathrm{~g}$, and $0 \pm 0 \mathrm{~g}$ of the fruit respectively. Increases in fruit intake (41 $\pm 6 \mathrm{~g} ; \mathrm{P}<0.0001$ ) between the reference and large fruit portions were observed among children who rated the fruit as "yummy."

Seventeen children rated the vegetable as tasting "yummy," seven as tasting "just okay" and six as tasting "yucky." Children who rated the vegetable as "yummy," "just ok" and "yucky" ate on average $52 \pm 9 \mathrm{~g}, 38 \pm 15 \mathrm{~g}$, and $0 \pm 0 \mathrm{~g}$ of the vegetable respectively. The 17 children who rated the vegetable as tasting "yummy" ate significantly more of the vegetable side dish $(17 \pm 6 \mathrm{~g} ; \mathrm{P}<0.05)$ when portion size was increased.

\section{Total Food and Energy Intake}

Total food intakes $(\mathrm{g})$ did not differ across conditions $(\mathrm{P}=0.28)$. Total food intakes were 389 $\pm 33 \mathrm{~g}, 386 \pm 33 \mathrm{~g}, 416 \pm 34 \mathrm{~g}, 384 \pm 35 \mathrm{~g}$ in the Reference, 2x Veg, 2x Fruit, and 2x F\&V conditions, respectively. In addition, total energy intakes did not differ across conditions $(\mathrm{P}=0.33)$. Total energy intakes were $368 \pm 33 \mathrm{kcal}, 366 \pm 33 \mathrm{kcal}, 383 \pm 34 \mathrm{kcal}, 342 \pm 34$ $\mathrm{kcal}$ in the Reference, 2x Veg, 2x Fruit, and $2 \mathrm{x} F \& \mathrm{~V}$, respectively. Energy intakes from milk $(\mathrm{P}=0.39)$ and the side dressing $(\mathrm{P}=0.68)$ also did not differ by condition. Energy intake from $\mathrm{F} \& \mathrm{~V}$, however, increased by $30 \pm 5 \mathrm{kcal}$ when portion sizes of both $\mathrm{F} \& \mathrm{~V}$ were doubled ( 58 
$\pm 5 \mathrm{kcal}$ vs. $88 \pm 9 \mathrm{kcal} ; \mathrm{P}<0.0001)$ as compared to the condition in which reference portions were served. Alternatively, children consumed less energy from the main entrée when both $\mathrm{F} \& \mathrm{~V}$ portions were doubled than when reference $\mathrm{F} \& \mathrm{~V}$ portions were served $(172 \pm 27 \mathrm{kcal}$ vs. $217 \pm 26 \mathrm{kcal} ; \mathrm{P}<0.05)$; a main effect of condition on pasta intake, however, was not observed. The shift in energy intake between the $\mathrm{F} \& \mathrm{~V}$ sides and the main entrée produced a $0.06 \pm 0.03 \mathrm{kcal} / \mathrm{g}$ decrease in the energy-density of the overall meal (including the beverage) $(0.94 \pm 0.03 \mathrm{kcal} / \mathrm{g}$ to $0.88 \pm 0.03 \mathrm{kcal} / \mathrm{g}$; $\mathrm{P}<0.05)$.

Much of the previous research on food portion size effects on children has focused on energy-dense foods (3-6). These results contribute to recent evidence that intake promoting effects of large portion sizes among children may extend to lower energy-density $\mathrm{F} \& \mathrm{~V}(10$, 11). A novel and key finding of this research was that the benefit of increasing vegetable portion size on vegetable intake was not negated by serving more fruit. While children expressed a higher relative preference for peaches than broccoli $(\mathrm{P}<0.0001)$, the results suggest that intakes of both F\&V can be promoted when larger portions of each food are served at the same meal. These results extend the work of Kral et al. (11) in which the portion sizes of a fruit as well as two cooked vegetables side dishes were doubled. Both studies observed increases in children's fruit intake when portions were doubled. The present study, however, observed increases in children's vegetable intake when larger portions were served. Differences in the broccoli preparation might explain the discrepancy between the studies. For instance, Kral and colleagues (11) served plain broccoli, whereas, the present study added butter and a side of salad dressing which have been shown to increase the palatability of vegetables (22).

Mixed results between portion size studies on vegetable intake might also be explained by differences in competing foods served at the meals. In one study with preschool children, increasing the portion size of carrots served alone with a side dip at the start of a meal increased carrot intake (10). In another study, increasing the portion sizes of F\&V served together did not lead to increased vegetable intake (11). Vegetable portion size effects, however, were observed among children who preferred the vegetable over all other foods served at the meal. Similarly, the present study demonstrated that intake promoting effects of larger vegetable portions were prominent among children who liked the vegetable. Future research is needed to determine how vegetable preparation and competing foods served at the meal affect vegetable intake.

Similar to Kral and colleagues (11), increasing F\&V portion sizes did not change total energy consumed by children at the meal, even though more $F \& V$ were consumed. Because of their high water content, the energy-density of $\mathrm{F} \& \mathrm{~V}$ is relatively low $(0.1-1.0 \mathrm{kcal} / \mathrm{g})$ (15). Interventions with adults have shown that reducing dietary energy-density by regular consumption of low energy-dense foods is an effective dietary strategy for weight management $(23,24)$. Furthermore, previous research has shown that decreases to food and dietary energy-density reduced preschool-aged children's energy consumption at meals (5, $9,25,26)$. In this study, the energy-density of total food consumed at the meal decreased by a small but significant amount. This occurred because children consumed less of the energydense main entrée and more of the $\mathrm{F} \& \mathrm{~V}$ side-dishes when larger portion sizes of both $\mathrm{F} \& \mathrm{~V}$ were served. These findings suggest that modest increases to $\mathrm{F} \& \mathrm{~V}$ portions can improve children's intake of healthy low energy-density $\mathrm{F} \& \mathrm{~V}$ without increasing overall energy intake at meals.

A few aspects of this study qualify interpretation of the findings. Although the sample was diverse with respect to children's race/ethnicity and weight status, the overall sample size was small, and the extent to which these findings generalize to children of different socioeconomic and family background cannot be determined from this particular study. The small 
number of children reporting "just ok" in the sample limited our ability to fully examine $\mathrm{F} \& \mathrm{~V}$ portion size effects across the entire liking spectrum. Lastly, more than half of the sample consumed the entire reference fruit portions, suggesting that the magnitude of the fruit portion size effect may have been inflated.

\section{Conclusion}

The results of this study provide new evidence that increasing the portion sizes of $\mathrm{F} \& \mathrm{~V}$ separately or together at meals can increase children's intake of both types of healthful foods. Moreover, serving larger portions of both $\mathrm{F} \& \mathrm{~V}$ may decrease the total energy-density of foods consumed at meals. Children who dislike $\mathrm{F} \& \mathrm{~V}$ will be unlikely to increase their intake when served larger portions without being exposed to feeding environments and strategies that increase their familiarity and acceptance of $F \& V$. To the extent that such strategies are successful in promoting acceptance, serving larger F\&V portions may have broad utility during interventions designed to promote healthy eating habits in children.

\section{References}

1. Krebs-Smith SM, Cook A, Subar AF, Cleveland L, Friday J, Kahle LL. Fruit and vegetable intakes of children and adolescents in the United States. Arch Pediatr Adolesc Med. 1996; 150:81-86. [PubMed: 8542012]

2. Guenther PM, Dodd KW, Reedy J, Krebs-Smith SM. Most Americans eat much less than recommended amounts of fruits and vegetables. J Am Diet Assoc. 2006; 106:1371-1379. [PubMed: 16963342]

3. Rolls BJ, Engell D, Birch LL. Serving portion size influences 5-year-old but not 3-year-old children's food intakes. J Am Diet Assoc. 2000; 100:232-234. [PubMed: 10670398]

4. Fisher JO, Rolls BJ, Birch LL. Children's bite size and intake of an entree are greater with large portions than with age-appropriate or self-selected portions. Am J Clin Nutr. 2003; 77:1164-1170. [PubMed: 12716667]

5. Fisher JO, Liu Y, Birch LL, Rolls BJ. Effects of portion size and energy density on young children's intake at a meal. Am J Clin Nutr. 2007; 86:174-179. [PubMed: 17616778]

6. Fisher JO. Effects of age on children's intake of large and self-selected portions. Obesity. 2007; 15:403-412. [PubMed: 17299114]

7. Fisher JO, Kral TV. Super-size me: Portion size effects on young children's eating. Physiol Behav. 2008; 94:39-47. [PubMed: 18155736]

8. Wansink B. Environmental factors that increase the food intake and consumption volume of unknowing consumers. Annu Rev Nutr. 2004; 24:455-479. [PubMed: 15189128]

9. Leahy K, Birch LL, Fisher JO, Rolls BJ. Reductions in entrée energy density increase children's vegetable intake and reduce energy intake. Obesity. 2008; 16:1559-1565. [PubMed: 18451770]

10. Spill MK, Birch LL, Roe LS, Rolls BJ. Eating vegetables first: the use of portion size to increase vegetable intake in preschool children. Am J Clin Nutr. 2010; 91:1237-1243. [PubMed: 20219955]

11. Kral TV, Kabay AC, Roe LS, Rolls BJ. Effects of doubling the portion size of fruit and vegetable side dishes on children's intake at a meal. Obesity (Silver Spring). 2010; 18:521-527. [PubMed: 19680238]

12. Cooke LJ, Wardle J. Age and gender differences in children's food preferences. Br J Nutr. 2005; 93:741-746. [PubMed: 15975175]

13. Birch LL. Preschool children's preferences and consumption patterns. J Nutr Educ. 1979; 11:189192.

14. Fisher JO, Birch LL. Fat preferences and fat consumption of 3- to 5-year-old children are related to parental adiposity. J Am Diet Assoc. 1995; 95:759-764. [PubMed: 7797805]

15. Gibson EL, Wardle J. Energy density predicts preferences for fruit and vegetables in 4-year-old children. Appetite. 2003; 41:97-98. [PubMed: 12880626] 
16. CSFII/DH KS Data Set and Documentation. The 1994 Continuing Survey of Food Intakes by Individuals and the 1994 Diet and Health Knowledge Survey. Virginia National Technical Information Service; 1994.

17. Birch LL. Dimensions of preschool children's food preferences. J Nutr Educ. 1979; 11:91-95.

18. Lohman, TG.; Roche, AF.; Martorell, R. Anthropometric standardization reference manual. Champaign, IL: Human Kinetics Books; 1988.

19. BMI for Children and Teens. Centers for Disease Control and Prevention; Web site. http:// www.cdc.gov/healthyweight/assessing/bmi/childrens_bmi/about_childrens_bmi.html [Accessed May 6, 2010]

20. Nutrient Data Laboratory. United States Department of Agriculture-Agricultural Research Service; Web site. http://www.nal.usda.gov/fnic/foodcomp/search/ [Accessed March 20, 2009]

21. U.S. Department of Health and Human Services and U.S. Department of Agriculture. Dietary Guidelines for Americans, 2005. 6. Washington, DC: U.S. Government Printing Office; Jan. 2005

22. Nicklas TA, Baranowski T, Baranowski J, Cullen K, Rittenberry L, Olvera N. Family and childcare provider influences on preschool children's fruit, juice, and vegetable consumption. Nutr Rev. 2001; 59:224-235. [PubMed: 11475448]

23. Rolls BJ, Roe LS, Beach AM, Kris-Etherton PM. Provision of foods differing in energy density affects long-term weight loss. Obes Res. 2005; 13:1052-1060. [PubMed: 15976148]

24. Ello-Martin JA, Roe LS, Ledikwe JH, Beach AM, Rolls BJ. Dietary energy density in the treatment of obesity: a year-long trial comparing 2 weight-loss diets. Am J Clin Nutr. 2007; 85:1465-1477. [PubMed: 17556681]

25. Leahy KE, Birch LL, Rolls BJ. Reducing the energy density of an entree decreases children's energy intake at lunch. J Am Diet Assoc. 2008; 108:41-48. [PubMed: 18155988]

26. Leahy KE, Birch LL, Rolls BJ. Reducing the energy density of multiple meals decreases the energy intake of preschool-age children. Am J Clin Nutr. 2008; 88:1459-1468. [PubMed: 19064504] 


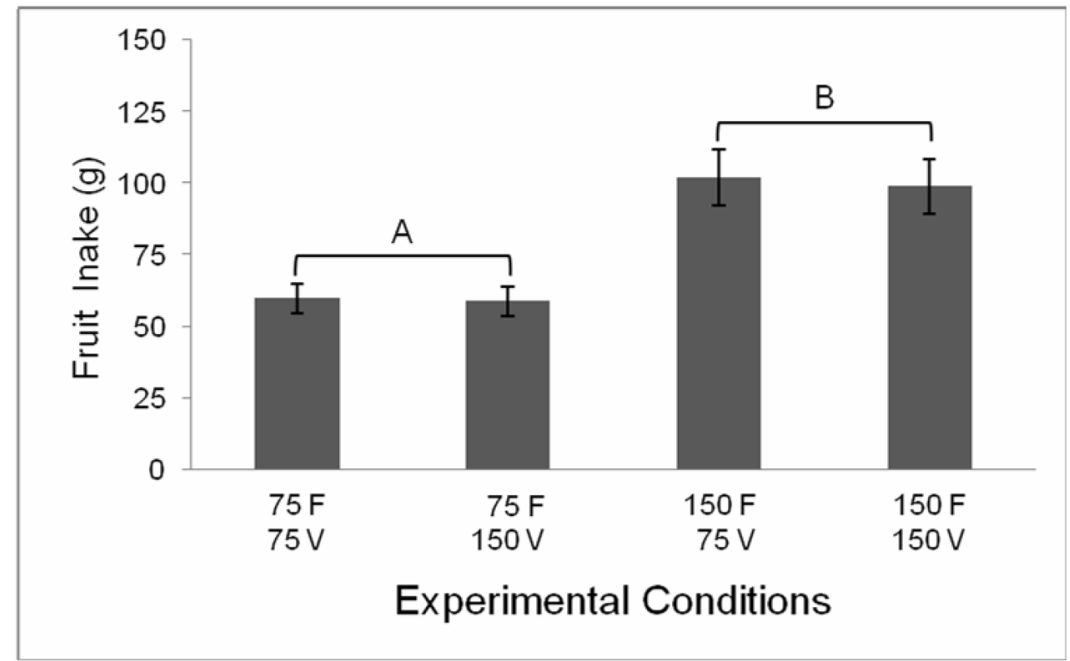

Figure 1.

Children's intakes of a fruit side dish (mean \pm SE) at a dinner meal across four experimental conditions ( $\mathrm{n}=30$ ). ( $75 \mathrm{~F}=\mathbf{7 5} \mathrm{g}$ fruit served, $75 \mathrm{~V}=\mathbf{7 5} \mathrm{g}$ vegetable served, etc.) Mixed linear model analysis indicated a main effect of fruit portion size on intake (A vs. B, $\mathrm{P}<0.05)$. The effect of portion size on children's fruit intake was not influenced by the portion size of vegetable offered. 


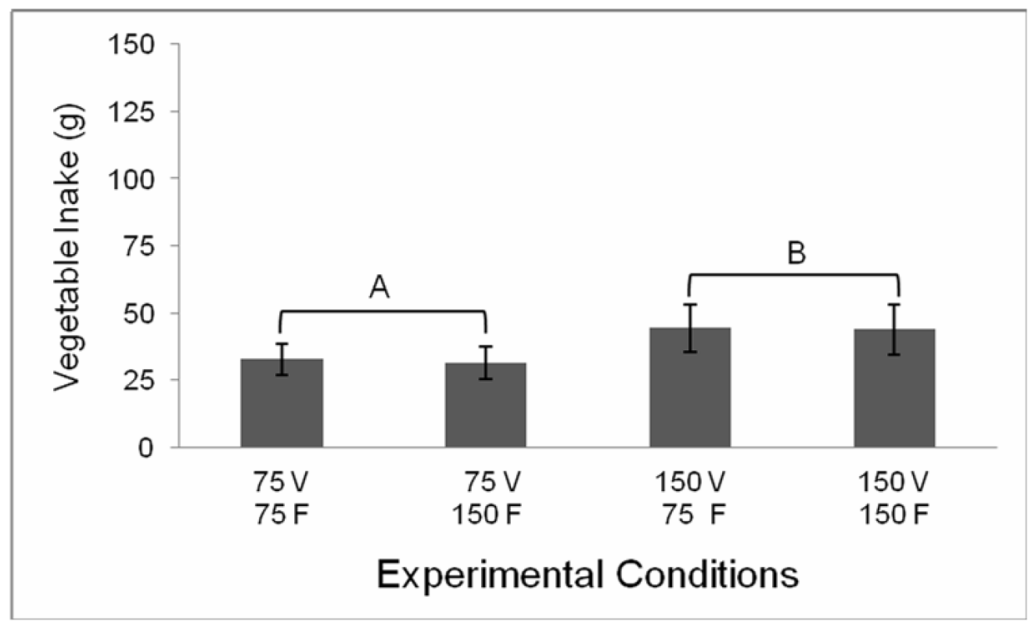

Figure 2.

Children's intakes of a vegetable side dish (mean \pm SE) at a dinner meal across four experimental conditions ( $\mathrm{n}=30$ ). ( $75 \mathrm{~V}=75 \mathrm{~g}$ vegetable served, $75 \mathrm{~F}=75 \mathrm{~g}$ fruit served, etc.) Mixed linear model analysis indicated a main effect of vegetable portion size on intake (A vs. B, $\mathrm{P}<0.05$ ). The effect of portion size on children's vegetable intake was not influenced by the portion size of fruit offered. 


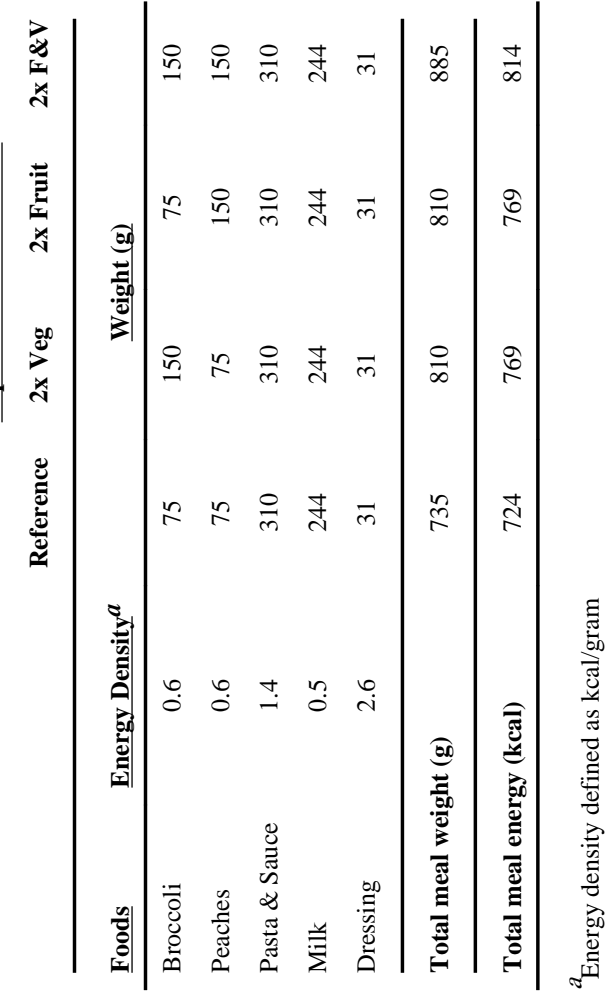

